\title{
Journal of Humanistic Mathematics
}

\section{Aesthetics in a Mathematics for Liberal Arts Project}

Jason Callahan

Saint Edward's University

Carol Gee

Saint Edward's University

Follow this and additional works at: https://scholarship.claremont.edu/jhm

Part of the Science and Mathematics Education Commons

\section{Recommended Citation}

Jason Callahan \& Carol Gee, "Aesthetics in a Mathematics for Liberal Arts Project," Journal of Humanistic Mathematics, Volume 7 Issue 1 (January 2017), pages 139-146. DOI: 10.5642/jhummath.201701.11. Available at: https://scholarship.claremont.edu/jhm/vol7/iss1/11

(C)2017 by the authors. This work is licensed under a Creative Commons License. JHM is an open access bi-annual journal sponsored by the Claremont Center for the Mathematical Sciences and published by the Claremont Colleges Library | ISSN 2159-8118 | http://scholarship.claremont.edu/jhm/

The editorial staff of JHM works hard to make sure the scholarship disseminated in JHM is accurate and upholds professional ethical guidelines. However the views and opinions expressed in each published manuscript belong exclusively to the individual contributor(s). The publisher and the editors do not endorse or accept responsibility for them. See https://scholarship.claremont.edu/jhm/policies.html for more information. 


\title{
Aesthetics in a Mathematics for Liberal Arts Project
}

\author{
Jason Callahan \\ Department of Mathematics, Saint Edward's University, Austin, TX, USA \\ jasonc@stedwards.edu \\ Carol Gee \\ Department of Mathematics, Saint Edward's University, Austin, TX, USA \\ carolg@stedwards .edu
}

\section{Synopsis}

We present and assess a project and its rubric developed and assigned in Mathematics for Liberal Arts, a general education course for non-science and nonbusiness majors, to incorporate different skills including aesthetic design, written and oral communication, and mathematical analysis to tackle a common optimization problem with an aesthetic slant: construct a beverage can (i.e., right circular cylinder) of a given volume while taking into account the cost of materials (i.e., surface area) and aesthetic qualities (e.g., the golden ratio).

\section{Introduction}

Mathematics for Liberal Arts is the course most commonly used to satisfy the general education requirement in mathematics among non-science and nonbusiness majors at our institution (a Catholic, liberal arts, Hispanic-serving institution of approximately 5000 students where most departments, including mathematics, are small and exclusively undergraduate). Each semester we coordinate four to six sections of the course, enrolling approximately 100175 students total, or 18-32 per section. Our standard syllabus covers a wide range of disparate topics such as logic, finance, statistics, voting theory, and mathematics in art and aesthetics. Prerequisite for the course is one year of college-preparatory high school algebra or equivalent skills, and the students taking it have a wide variety of mathematical abilities and backgrounds. 
What they mostly share in common is apprehension and reluctance, if not anxiety, for one more mathematics course as required in our general education curriculum; $[3,5,6]$ make similar observations. We therefore strive to offer a course that is educational (that is, intentionally not remedial), relevant, and accessible to students of varying backgrounds and abilities.

In Fall 2008, the curriculum of Mathematics for Liberal Arts was revised to include:

1. A focus on quantitative literacy; that is, being able to think mathematically, e.g., when reading a newspaper or grocery shopping, rather than just solving textbook problems.

2. Just-in-time review of prerequisite material: fractions, exponents, simple equations, etc.

3. An emphasis on "relevant" and "interesting" topics such as numbers in perspective, personal finance, probability and statistics, geometry in art and architecture, voting theory, etc.

4. Projects with an emphasis on technical and logical communication.

5. Room in the schedule for special topics of particular interest to the instructor.

We also updated our textbook and began to use Using and Understanding Mathematics: A Quantitative Reasoning Approach by Jeffrey Bennett and Williams Briggs [1].

In this paper, we present one of the projects that we developed for Mathematics for Liberal Arts to incorporate different skills, including aesthetic design, written and oral communication, and mathematical analysis. We also share a rubric we have been using to assess student work on the project.

\section{Projects in Mathematics for Liberal Arts}

The current version of Mathematics for Liberal Arts involves three projects distributed throughout the term. While developing the course, we strove in particular to make the projects interesting (by including open-ended aspects that make every group's project unique), relevant (by including real-world problems such as calculating federal income taxes and a family budget), and 
encompassing (by including oral presentations, written reports, and aesthetic design of visual aids to incorporate different skills). The pedagogical basis and impact on student outcomes of such curriculum redesign and inclusion of projects are explored in $[2,3,4,5,6,8]$. To develop students' abilities to collaborate and communicate mathematically, all three projects were completed in groups of three or four outside of class over the span of three weeks and required both written reports and in-class oral presentations that included the design and use of visual aids.

The first project, due in the fifth week of our fifteen-week semester, prompted students to use a four-step problem-solving process modified from Polya [7] to address an open-ended problem unique to each group. The second project, due in the tenth week of the semester, prompted students to create a budget for a fictional family situation unique to each group. The third project, which is the topic of this paper, was due in the fifteenth and final week of the semester. Students were asked to tackle a common optimization problem with an aesthetic slant:

Construct a beverage can (i.e., right circular cylinder) of a given volume while taking into account the cost of materials (i.e., surface area) and aesthetic qualities (e.g., the golden ratio).

At this point of the term we typically would have finished covering the units on problem-solving with geometry, proportion, and the golden ratio in our textbook [1], though students were prompted to do more research on aesthetic and ergonomic considerations on their own.

\section{Project Prompt and Rubric}

Drawing on the fictional and creative aspects of the second project, this third project regarded our groups as freelance industrial engineering and design firms (for which they had to devise a name and logo) that have been asked to design a beverage can. Playing on our school's mascot (the "Hilltopper"), which in turn inspires many other names on our campus (e.g., students purchase meals with "Topper Tender" and listen to "Topper Radio"), and recent popularity of energy beverages, we prompted each group to propose a right circular cylindrical can design with a volume of exactly 355 cubic centimeters for a new campus beverage, "Topper Turbo Energy Drink". Each group then wrote a proposal recommending dimensions for their can, taking all three of the following criteria into consideration. 
1. Minimal cost of materials: what cylinder dimensions minimize the amount of materials used (i.e., the surface area of the can) while maintaining a volume of exactly 355 cubic centimeters?

2. Minimal distribution costs: what cylinder dimensions will minimize the wasted air space when packing six cans (two rows of three cans) into a rectangular box?

3. Aesthetic/ergonomic considerations: aside from materials and distribution costs, what else factors into an "ideal" can's dimensions?

While the first criterion is a standard and straightforward problem in calculus (see, for instance, Example 2 in Section 4.6 on optimization problems in [9]), most of our students in Mathematics for Liberal Arts have not had calculus. Furthermore those students who have had some calculus experience were not allowed to use it for this project. Instead, we asked that the groups experiment with different dimensions, all with exactly the desired volume, until they got within one centimeter of the optimal dimensions through trial and error.

For the second criterion, too, we prompted the groups to experiment with different dimensions and compare in each case the volume of a box exactly big enough to fit the six cans to the total volume of the six cans themselves. Many groups were surprised to find that the wasted air space remained the same regardless of the dimensions of the can and were inspired to explore why this was the case.

Finally, for the third criterion, groups were prompted to read about the golden ratio as it relates to rectangles, art, marketing, human anatomy, and aesthetics in general as discussed in our textbook [1] and to do additional research on their own.

With all three criteria taken together, there was no one correct answer to this project as a whole. Groups found that the dimensions best satisfying one of the criteria may not be the best solution for another criterion. At the end of the project, each group was asked to weigh all the considerations, make a single recommendation, write a marketing proposal to present and justify this recommendation, and build a prototype according to the following guidelines. 
1. The proposal began with a typed cover letter of length no more than one page, summarizing the group recommendation and addressing why this recommendation best meets the criteria. Groups were prompted to create an address for their firm and follow standard business letter format.

2. The cover letter was to be followed by an appendix showing all of the calculations and addressing each of the criteria as justification for the proposed design. At least three different potential dimensions with volume exactly 355 cubic centimeters were to be tried including wellformatted calculations and typed explanations.

3. The prototype was a three-dimensional model of the can design, using the actual proposed dimensions (1:1 scale). The prototype had to be able to withstand gentle handling and was graded on its appearance: part of the project grade was subjective, based on a class vote among design entries. In addition to showcasing the can's dimensions, groups were prompted to make their proposal more competitive through aesthetic design of the can's label.

4. In class each group gave a sixty-second presentation to pitch their design proposal to the Topper Turbo executive board (their classmates and instructor).

We graded this project according to the following rubric; the first eighty points were earned as a group, and the last twenty were earned individually to ensure every student's participation both on the project and during inclass presentations.

Format: organization and professional tone (10 points).

Conclusion: clearly stated in the cover letter and supported in the appendix (10 points).

Materials cost analysis: calculations, analysis, and formatting (15 points).

Distribution cost analysis: calculations, analysis, and formatting (15 points).

Aesthetic/ergonomic analysis: calculations, analysis, and formatting (15 points). 
Prototype and oral presentation: the three-dimensional model has the same dimensions as in the proposal and could withstand handling, and class vote of the "best" design (15 points).

Class evaluation: voting in class on the "best" design ( 5 points).

Group evaluation: completing an evaluation of the contributions of each member of one's group (5 points).

Individual evaluation: evaluation of one's contributions by the other members of one's group (10 points).

The in-class presentation of projects coincided with coverage of voting methods in our textbook [1]. By instructing the students to cast their vote as a preference schedule - first, second, third place - we were able to use these ballots to illustrate the difference between majority rule, plurality, single and sequential runoffs, Borda count, and pairwise comparisons or Condorcet method. In contrast to the project on voting theory in [4] or beginning the course with it as in [5], we used students' votes during the evaluation part of our project to introduce and teach voting theory.

\section{Concluding Remarks}

Students seemed to enjoy this project and the opportunity to create a threedimensional model to scale as determined by mathematical and aesthetic analysis. They employed a variety of media, including sculpting clay, cardboard, aluminum, and plastics. They also seemed to enjoy weighing mathematical "solutions" against aesthetic and ergonomic considerations. The unit on the golden ratio inspired many of them to consider why objects such as buildings, credit cards, artwork, and electronic devices such as cell phones look the way they do, whether a beverage can that minimizes surface area is the most aesthetically pleasing, and if not, how to weigh such considerations against one another. Some took a more analytical route and argued for the importance of minimizing materials cost, while others felt aesthetics should trump cost considerations, arguing that no one will choose to purchase a beverage whose container has visually unappealing or ergonomically uncomfortable dimensions. Some took this a step further, incorporating the golden ratio not only into the dimensions of the can (so that it would appear to 
be a golden rectangle in crossection) but also in the can's label and firm's logo, e.g., by incorporating golden rectangles and spirals; see Figure 1 for examples.

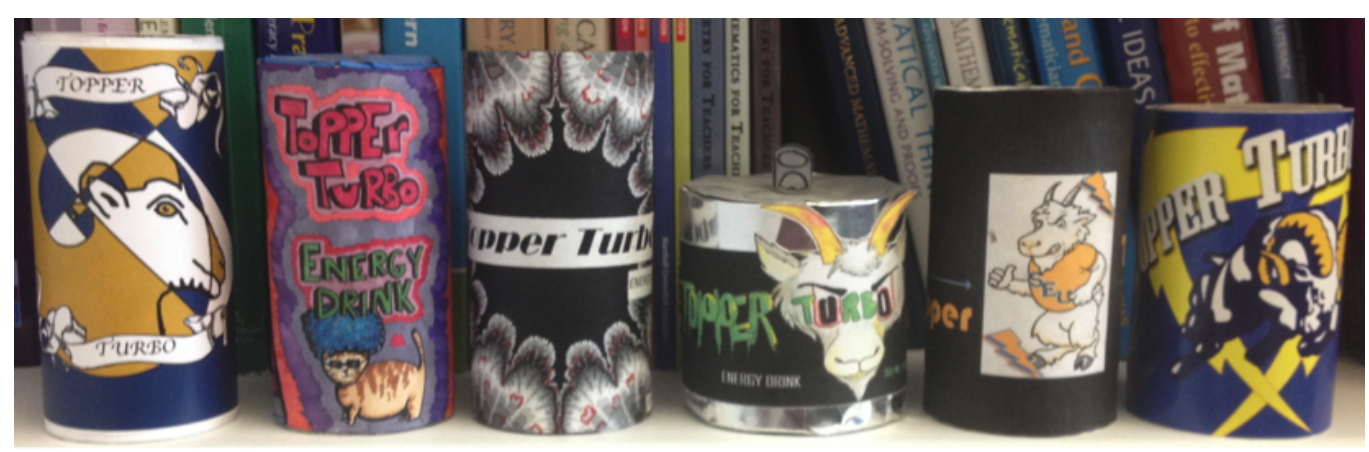

Figure 1: Examples of prototypes built by students.

By this point in the semester, after the first two projects, students were comfortable working in groups, which remained the same throughout the semester unless personal issues necessitated change, and communicating mathematics through written reports and in-class oral presentations. In fact, some students wore costumes and affected character personas for their presentations, giving them an additional element of a creative performance.

Thus, as a whole, we feel our efforts to incorporate different skills including aesthetic design, written and oral communication, and mathematical analysis into this project were successful. The rubric grades reflected this: nearly all students successfully completed and passed this project each semester even when taught by different instructors, including adjunct faculty, who found the project simple and straightforward to assign and grade. Likewise, student opinions on course evaluations routinely praised the project and the opportunities for creativity it afforded.

This project played a significant role in our successful curricular reform, helping us offer a course that is educational, relevant, and accessible to students of varying backgrounds and abilities. While $[3,4,6]$ describe similar success harnessing student creativity, we attribute ours to upholding aesthetic considerations equal to those of cost minimization. We look forward to seeing what students will do with the project in the future. For instance, it will be interesting to see if they will attempt to use technologies such as 3D printing, and if so, how this will affect the creative and aesthetic aspects of the project. 
$146 \quad$ Aesthetics in a Mathematics for Liberal Arts Project

\section{References}

[1] Jeffrey Bennett and William Briggs, Using and Understanding Mathematics: A Quantitative Reasoning Approach, 5 ${ }^{\text {th }}$ edition, Pearson, Boston, 2010.

[2] Jennifer Clinkenbeard, "Attitudes and experiences in liberal arts mathematics," Journal of Humanistic Mathematics, Volume 5 Number 2 (2015), pages 26-50. Available at http://scholarship.claremont. edu/jhm/vol5/iss2/4/, accessed on January 26, 2017.

[3] Judith V. Grabiner, "How to teach your own liberal arts mathematics course," Journal of Humanistic Mathematics, Volume 1 Number 1 (2011), pages 101-118. Available at http://scholarship.claremont. edu/jhm/vol1/iss1/8/, accessed on January 26, 2017.

[4] Reva Kasman, "Balancing structure and creativity in culminating projects for liberal arts mathematics," PRIMUS, Volume 24 Number 6 (2014), pages 480-490.

[5] Gregory A. Kelsey, "Social choice in a liberal arts mathematics course," PRIMUS, Volume 23 Number 2 (2013), pages 161-172.

[6] Linda McGuire, "The mathematics correspondent: An engaging and effective group project for a liberal arts mathematics course," PRIMUS, Volume 23 Number 3 (2013), pages 195-207.

[7] George Polya, How to Solve It, Princeton University Press, Princeton, 1957.

[8] Robin Rufatto, Holly Dickin, Alina Florescu, Crystal Lorch, Ralph Bremigan, and John Lorch, "Learner-centered pedagogy in a liberal arts mathematics course," PRIMUS, Volume 26 Number 9 (2016), pages $863-877$.

[9] James Stewart, Calculus: Concepts and Contexts, $4^{\text {th }}$ edition, Brooks/Cole, Belmont CA, 2010. 